\title{
estudos semióticos
}

\author{
www. revistas. usp. br/esse
}

\section{A. J. Greimas, um projeto teórico em construção}

Anne Hénault *

Tradução de Juliana Di Fiori Pondian **

\begin{abstract}
Resumo: Depois de recuperar as principais etapas pelas quais Greimas atravessou a linguística para fundar, concretamente, a semiótica geral, mostramos como o conceito de imanência define a identidade da semiótica que Greimas convidava a construir e a praticar. O princípio de imanência é o instrumento conceitual que permite atualizar, descrever e hierarquizar os jogos relacionais abstratos que constituem a gramática profunda das línguas e da linguagem. O novo saber que resulta da emergência da semiótica está inteiramente ligado a esse tipo de funcionamento mental cujo saber matemático constitui outro exemplo.
\end{abstract}

Palavras-chave: Imanência, teoria, metalinguagem, prática, gramáticas abstratas

A. J. Greimas (1917-1992) foi um homem de força moral excepcional, que soube transmudar, num engajamento científico bastante fecundo, incontáveis provações que lhe foram impostas pela História do século XX. Sua biografia será publicada em breve ${ }^{1}$; por isso, diremos apenas algumas palavras sobre a vida pessoal de Greimas antes de nos concentrarmos em seu projeto científico, de pesquisador.

A pessoa de Greimas retinha, frequentemente de maneira completa e definitiva, os que dele se aproximavam. Visionário, porém, perspicaz, ele era mais dotado do que qualquer um para aquilo que, com Dostoiévski, chamamos "o discernimento das almas". Ele era para o grupo de alunos totalmente engajados em seu projeto teórico, ao mesmo tempo, Sócrates em meio a seus discípulos nos jardins da Academia e Albert Einstein, solitário na descoberta da teoria da relatividade: Greimas cultivava o paradoxo e a gozação, zombava constantemente de si mesmo e tentava nos fazer admitir que ele era apenas um "caipira do Danúbio”, mesmo que já tivesse deixado em Kaunas, Vilnius e outros lugares da Lituânia, assim como em Grenoble, onde descobriu a filologia, desde 1935, a lembrança de um rapaz elegante, a quem não desagradava passar por dândi.
Ele terá sido o fundador de uma corrente de pesquisa que não demorou a interessar ao mundo inteiro, depois de ter estado totalmente em evidência em Paris, entre 1966 e 1980. Foi um pensador que esteve na moda e, no entanto, desconfiava visceralmente daquilo que estava na moda. Suas leituras não seguiam em nada os modismos e obedeciam apenas a imperativos fundamentais. Essa linha de conduta, bastante sistemática e que nunca falhava, terá feito dele um passeur, capaz de manter a exigência epistemológica dos grandes mestres do passado (os Poincaré, os Cavaillès, os Reichenbach ou Robert Blanché e, antes deles, o pensamento racional do período clássico, Descartes, Port-Royal, Leibniz, Kant, Nietzsche, Husserl). Ele seguia meticulosamente as lições dos mestres da epistemologia, aos quais jamais deixava de se referir. Em Greimas, a instalação de novos conceitos semióticos se fazia, com infinitas precauções, em continuidade com a grande corrente racionalista que marcou as etapas de construção do pensamento científico e os desenvolvimentos da ciência contemporânea. Ele ignorava os comprometimentos ideológicos e se mostrava de um rigor absoluto no plano do saber, sendo ao mesmo tempo um verdadeiro humorista: jamais deixava de fazer algumas piadas afiadas, sempre que a comédia

\footnotetext{
* Professora emérita da Universidade de Paris IV-Sorbonne, França, e responsável pela coleção "Formes Sémiotiques" da PUF (Les Presses Universitaires de France). Endereço para correspondência: 〈anne.henault@beaurecueil.org > .

** Pós-doutoranda do Programa de Estudos Linguísticos e Literários em Inglês do Departamento de Letras Modernas da Universidade de São Paulo (FFLCH-USP). Endereço para correspondência: 〈julianapondian@gmail.com 〉.

${ }^{1}$ Sobre os diversos avatares da vida de Greimas, teremos em breve um documento excepcional, com a biografia completa que será lançada por Tom Broden. Ver também Michel Arrivé (2007), capítulo VIII.
} 
humana lhe dava oportunidade.

Para uma caracterização global de Greimas, pesquisador, fala-se com frequência de ambição, ousadia, profundidade, rigor flexível. Acrescentemos o "gosto pelo paradoxo e pelas hipóteses extremas". O autor de Semântica estrutural (1976 [1966]) ofereceu às ciências da linguagem uma linha teórica que - porque era do começo ao fim racional, em conformidade com a ampla visão científica de Saussure e Hjelmslev - daria objetividade e força demonstrativa à abordagem das significações postas em circulação na vida social.

Greimas só pôde sustentar essa proposta porque sabia insuflar um tipo de vida concreta a espaços mentais, tidos como áridos e secos. Sob sua palmatória, o conjunto de noções abstratas e de procedimentos que constituem as aquisições e o organon da teoria ganhava vida assim como ganham vida conceitos matemáticos em debates entre os pesquisadores mais criativos. Daí as controvérsias planetárias suscitadas, no passado, pelas noções de "quadrado semiótico" ou "percurso gerativo" e pela questão da "conversão" entre níveis de sentido ou o recente conturbado debate transatlântico sobre o conceito de "Imanência" na linguística e na semiótica ${ }^{2}$.

Eis por que este texto será dedicado essencialmente à recuperação das principais etapas que marcaram a aventura prometeica que foi o encaminhamento teórico de Greimas, antes de formular algumas observações acerca do que o conceito fundamental de imanência representa hoje para a semiótica.

\section{Uma aventura prometeica: dar à semiótica o estatuto de um projeto do tipo científico}

\subsection{Descobrir e refletir sobre os precur- sores da racionalidade linguística}

Greimas insistiu muitas vezes na inspiração que lhe despertaram Saussure, de um lado, e a escola dinamarquesa (principalmente Hjelmslev e Uldall), de outro: ele sempre se mostrou irrevogavelmente cativado pelo gesto fundador que singulariza o Curso de Saussure, um movimento de abstração até então desconhecido nas Ciências Humanas ${ }^{3}$. Pela primeira vez, um pesquisador ousava pensar que a substância do sentido é menos reconhecível, objetivamente, do que sua forma (seja da expressão ou do conteúdo) e esse mesmo pesquisador assumia totalmente a ideia de que essa forma é, em si mesma, feita apenas de sistemas de relações livres de investimentos semânticos e desprovidos de termos positivos. Perspectiva vertiginosa e excitante para o espírito, uma vez que constitui um outro campo do saber e uma maneira radicalmente nova, literalmente inaudita, de conceber e de exercer a apreensão e a explicação do sentido, que assim se desenham.

O segundo deslumbramento de pura racionalidade frequentemente mencionada por Greimas lhe foi inspirada pelos Prolegômenos a uma teoria da linguagem (1975 [1961]), de Hjelmslev. Segundo ele, as visões de Saussure ficavam explícitas e se tornavam apreensiveis graças a esse monumento de total abstração elaborado pelo pesquisador dinamarquês, em diálogo com seu jovem colega Uldall. Aos olhos de Greimas, os Prolegômenos evidenciavam os primeiros esboços dos espaços mentais que seriam identificados e tratados como planos de imanência para fundar, desenvolver e aplicar a teoria das significações. Greimas um dia me descreveu ${ }^{4}$ esse texto como um palácio de cristal de beleza e claridade deslumbrantes, uma vez que começava a tornar claro e paradoxalmente concreto o jogo infinitamente complexo de relações abstratas que subjaz à circulação das significações na e pela vida social.

Uma terceira leitura quase contemporânea às duas precedentes, a do livro Morfologia do conto maravilhoso (1984 [1928]), de V. Propp, feita em binômio com Roland Barthes (no ano em que eles se inspiravam um no outro enquanto eram jovens professores de francês em Alexandria, no Egito), não despertou em Greimas um fervor racional do mesmo tipo; por estar em concordância com alguns outros trabalhos dos quais ele tinha conhecimento, o trabalho de Propp contribuiu essencialmente para a prática semiótica, ao começar a isolar constantes figurativas assinalando o nivel propriamente narrativo de uma história. Na verdade, ainda que as análises de Propp continuassem muito dependentes do nível figurativo dos contos, elas ofereciam, como as de Souriau ou de Tesnière ${ }^{5}$, o início dos cálculos narrativos fundados sobre as regularidades quase formais que afloravam na superfície dos contos ou da gramática frasal. Essa prática inspirou em Greimas um trabalho de simplificação, reorganização e algebrização dos componentes das listas (de personagens e de ações/funções) levantadas por Propp. Foi assim que a sintaxe narrativa não figurativa começou a se desenhar e a se impor, segundo sua engenharia racional do começo ao fim, graças a um esforço de metalinguagem desconhecido até então nas ciências humanas.

Desse mesmo movimento, a estrutura em camadas do relato, como massa folhada (que Lévi-Strauss havia

\footnotetext{
${ }^{2}$ Ver Zinna, Alessandro Zinna; Ruiz Moreno, Luisa (éds.)., 2014 et 2015.

3 Cf. um breve resumo da teoria de Saussure (16 páginas) em Anne Hénault, 2010: “The Saussurean Heritage". In: Cobley, Paul (éd.). The Routledge Companion to Semiotics. London: Routledge, 2010.

${ }^{4}$ Greimas, Entrevista inédita com Anne Hénault.

${ }^{5}$ A. J. Greimas. Sémantique structurale (1966), pp.173-182.
} 
proposto como uma das chaves de leitura dos mitos transmitidos pela tradição oral), começava a se impor ao espírito de Greimas como reconhecível e incontornável, metodologicamente. Esses primeiros passos em direção a profundezas abstratas da linguagem mobilizavam todos os tipos de operações racionais. Como diferenciar e listar essas primeiras descobertas tendo em vista a descrição e a hierarquização dos planos de imanência da língua e da fala?

Para isso, era necessário tentar precisar as ligações que a elaboração da teoria semiótica estabeleceria com a prática. Que ligações era preciso enxergar, exatamente, entre aplicações funcionais (doravante tornadas necessárias pelas novas tecnologias, por exemplo, para o tratamento de Big data) e práticas de laboratório (que não ultrapassam os espaços de pesquisa) e, portanto, entre a teoria aplicada e a teoria geral?

Em Saussure, diversos aspectos mentais mobilizados por todas essas pesquisas permaneceram distintos. Michel Arrivé sublinha isso abundantemente ${ }^{6}$ : Saussure não parecia unir, de fato, suas visões linguísticas a seus trabalhos de análise de poemas ou de lendas antigas. Dessa forma, desde o início de seu percurso como semioticista, Greimas foi dependente das proposições de Hjelmslev, de um lado, e de C. Lévi-Strauss, de outro, para conectar o nível narrativo aos jogos relacionais elementares das estruturas profundas opositivas. Foi assim que ele conseguiu amplificar e concretizar as visões de Saussure - tão fervilhantes, ao mesmo tempo, por sua radicalidade visionária e força verbal, a energia de sua formulação.

Do que pudemos observar por nós mesmos em diversos manuscritos - notas científicas e correspondências - de Saussure, cada vez mais amplamente acessíveis, o fato de ele recorrer à noção semiótica que designava como "semiologia" tinha, antes de tudo, natureza lógica: a ideia da semiologia lhe permitia elaborar melhor a ideia linguística, incluindo as línguas ditas "naturais" no conjunto mais vasto das diferentes linguagens não verbais presentes nas sociedades humanas, animais e mesmo vegetais, ou seja, em todos os sistemas de comunicação que caracterizam o reino dos seres vivos. Essa prudência epistemológica é, precisamente, o que autoriza (no sentido etimológico do termo) a extensão da semiótica à biologia e, portanto, às diversas comunicações internas (intracorporais) ou externas (intraespécies ou interespécies) do ser vivo -

orientação a partir de então capital para a pesquisa semiótica contemporânea ${ }^{7}$.

\title{
1.2 Fugir da lexicologia
}

Em Sémiotique en jeu (Arrivé; Coquet, 1987), Michel Arrivé coloca a seguinte questão: Como um linguista obscuro, recém-naturalizado francês, Julien/Guy Greimas veio a se metamorfosear nesse famoso semioticista, mundialmente conhecido, Algirdas Julien Greimas?

Inicialmente (1945-1946), Greimas dedicava-se à lexicologia, conforme faziam na época os doutorandos de Brunot e Bruneau. Em 1948, ele defende sua tese a partir de um corpus exaustivo que reunia todas as publicações sobre moda impressas em Paris durante o ano de 1830. Esse trabalho foi marcado por uma ativa pesquisa de método, lista, análise e classificação do vocabulário parisiense da moda em 1830, a fim de depreender nesse léxico os muitos traços políticos, econômicos e sociais característicos da sociedade romântica parisiense (Greimas, 2000).

À questão que lhe foi colocada em Cerisy, em 1983: "Que papel [em sua vida de pesquisador] teve a lexicologia estrutural?"8, Greimas respondeu:

\begin{abstract}
Acredito que a função de minha passagem pela lexicologia é a função estimulante do fracasso. Foi porque vi, depois de um trabalho de cinco ou seis anos, que a lexicologia não levava a lugar algum - que as unidades /lexemas/ ou /signos/ não conduziam análise alguma, nem permitiam a estruturação, a compreensão global dos fenômenos - que entendi que é "sob" os signos que as coisas acontecem. Evidentemente, uma semiótica é um sistema de signos, mas sob a condição de ultrapassar esses signos e observar o que está subjacente a eles. Foi preciso que eu vivesse esse tipo de postulado, ou de intervenção, para realmente poder me engajar nele. E eu vivi a não pertinência do nível dos signos em minha experiência lexicológica [...] nos anos 1940-1950. (Arrivé; Coquet, 1987, p. 302-303) ${ }^{9}$
\end{abstract}

Nota-se aqui a insistência no "experimentado", no vivido: a decisão científica não é puramente abstrata. A íntima convicção repousa sobre uma "experiência" vivida, assegurada, de alguma forma, pela sinceridade, ou ainda, pela verdade do corpo-próprio.

\subsection{Integrar a narratologia}

\footnotetext{
${ }^{6}$ Arrivé, 2007, cap. III e cap.VI.

7 Claus Emmeche. Biosemiotics (2008); Jean-Didier Vincent. Biologie des passions (1994) et Biologie du couple (2015).

8 Tradução nossa para o trecho original: "Quel rôle la lexicologie structurale a-t-elle joué [dans votre vie de chercheur]?"

9 Tradução nossa para o trecho original: “Je crois que la fonction de mon passage par la lexicologie, c'est la fonction stimulante de l'échec. C'est parce que j'ai vu, après un travail de cinq ou six ans que la lexicologie ne menait nulle part - que les unités /lexèmes/ ou /signes/ ne menaient à aucune analyse , ne permettaient pas la structuration , la compréhension globale des phénomènes - que j'ai compris que c'est "sous" les signes que les choses se passent. Evidemment, une sémiotique, c'est un système de signes, mais à condition de dépasser ces signes et de regarder ce qui se passe sous les signes. Ce genre de postulat ou d'intervention, il a fallu que je le vive pour vraiment y adhérer. Pour moi, la non-pertinence du niveau des signes, je l'ai vécue dans mon expérience lexicologique \{... \} dans les années 1940-1950."

${ }^{10}$ Ver em A. J. Greimas, La mode en 1830 (2000), uma seleção de seus "Escritos de juventude".
} 
Nos dez anos seguintes, Greimas, então, puramente linguista, publica alguns artigos ${ }^{10}$ enquanto redige, na Turquia, uma primeira versão de Semântica estrutural, a qual ele destrói totalmente antes de reescrevê-la e testá-la em Paris no ano de 1964, num seminário proferido no Instituto Henri Poincaré (Centro de Matemáticas Avançadas de Paris). Finalmente, a obra foi publicada pela primeira vez em 1966.

Esse volume, que misturava vastos panoramas epistemológicos, uma construção teórica que já tinha tomado forma e algumas tentativas de aplicação às mitologias sociais, à psiquiatria e à abordagem de textos literários, iria modificar por muito tempo a paisagem das ciências humanas.

O período de 1964 a 1970 foi marcado pela confirmação do movimento teórico-prático iniciado por essa obra: a semiótica progride em direção a uma narratologia abstrata que conduz Greimas a falar em "narratividade generalizada". O essencial dessa evolução se lê em duas coletâneas de artigos intituladas Sobre o sentido (1975, Du Sens [1970]) e Sobre o sentido II (2014, Du Sens II [1983]). Construindo seu caminho, Greimas adquire um estilo de escrita bem mais demonstrativo e registra os resultados de seus cálculos narrativos com a ajuda de uma metalinguagem algébrica. Essa escrita "simbólica", no sentido que Hans Reichenbach a concebia, culmina nessas formulações minimalistas, graficamente biunívocas e radicalmente não verbais que os especialistas em literatura ou em filosofia especulativa com frequência reprovaram em Greimas, sem mensurar as possibilidades que elas criavam. Podemos agora conhecer melhor suas aplicações a partir do tratamento automático de dados recolhidos pela informática, como é o caso hoje dos vertiginosos cálculos narrativos impostos pelos Big data. Com essa escrita "simbólica", a análise narrativa escapa à necessidade de frasear seus resultados em explicações verbais, sempre suscetíveis a imprecisões e ambiguidades das línguas naturais. Assim, a semiótica sai do círculo vicioso da fatalidade da expressão verbal à qual Benveniste acreditou que ela estava condenada, e mostra que é possível dar conta do sentido de outra forma.

\subsection{Um projeto que constrói, passo a passo, uma teorização realmente ci- entífica}

A partir de 1970, com Sobre o sentido (1975 [1970]), o que se apresentava como magma de matéria em fusão em Semântica estrutural (1976 [1966]) passa a ser formulado como uma "teoria", de acordo com aqueles que compreendiam Saussure e, depois, Hjelmslev e Uldall. Estamos aqui próximos do sentido dado a esse termo pelas ciências físicas ou matemáticas; certamente, não se trata ainda de uma teoria situada no nível das ra- cionalidade de uma teoria matemática, mas alguns matemáticos, como René Thom e seu aluno, Jean Petitot, jamais tiveram dificuldades em declarar que as primeiras realizações desse trabalho deram início ao percurso de construção de uma verdadeira ciência da linguagem e tendiam a uma teoria autenticamente científica. Para eles, esse estágio intermediário que Greimas nos permitiu atingir poderia ser comparado à biologia naturalista antes da revolução da biologia molecular, ou ao estatuto da química antes das teorias quânticas.

Como quer que seja, fica claro o tipo de expectativa que insuflou os perpétuos esforços de abstração e reorganização, no campo da imanência, dos resultados provisoriamente adquiridos (como vimos, foi isso que fez Greimas a partir dos resultados de Propp) pela Escola de Greimas. É com esse espírito que convém ler os trabalhos de Jean-Marie Floch, Françoise Bastide, J. F. Bordron, Pierre Boudon, Jacques Fontanille, Jean Petitot, Claude Zilberberg, Anne Hénault e tantos outros pesquisadores engajados. Poderemos ver igualmente alguns exercícios práticos de aplicação dessa "teoria" em diversos campos da vida social na coletânea Questions de sémiotique (Hénault, 2002).

Interrompemos aqui a evocação do percurso mental que permitiu a Greimas ancorar, cada vez mais demonstrativamente, a teoria geral chamada "teoria standard". As mudanças ocorridas em seguida, particularmente com Da imperfeição (Greimas, 2002 [1987]) e Semiótica das paixões (Greimas; Fontanille, 1993 [1991]) deram à pesquisa uma diversificação necessária, abrindo-se na direção das paixões e do sensível em geral. Esses novos terrenos oferecem à semiótica múltiplas perspectivas que reconduzem ao primeiro plano de suas preocupações a questão da imanência.

\section{Os canteiros da imanência}

Em meio à primavera de 2013, uma primavera fria, perturbada por uma série de feriados, o Seminário de Semiótica Geral, evento quinzenal, que na época acontecia às quartas-feiras na Sorbonne, foi totalmente interrompido (por causa dos feriados nesse dia) durante todo o mês de abril e até a metade de maio. No entanto, como o encontro de 3 de abril havia sido particularmente estimulante e animado, com um debate que começava a virar disputa, ele acabou continuando - durante todo esse período de interrupção dos encontros - numa espécie de seminário virtual que tinha o ar de uma guerrilha transcontinental (México e América Latina, via e-mails, entraram nessa furiosa controvérsia que beirava a injúria) sobre assuntos tão abrasados como o dualismo de Descartes ou o pretenso monismo de Spinoza lido por Deleuze, ou ainda sobre a questão crucial da imanência, da qual, aos olhos de alguns, tinha se tornado urgente se livrar. 
Será que esse conceito não corresponderia a um tipo de dogmatismo totalmente ultrapassado? Não deveria ser eliminado da teoria, uma vez que, para muitos, parecia estar em contradição com todos os trabalhos que investiram na corporeidade do sentido ${ }^{11}$

É assim, portanto, que em Paris, em 2013, por e-mails ehipertextos interpostos, vivemos as Provinciais de Pascal em escala planetária. Foi uma divina surpresa para nós ver acontecer um fenômeno como tal nesses tempos de desilusão, quando, ao que parece, os trintões não querem mais "quebrar a cabeça", os quarentões provavelmente não comprarão mais livros de verdade e os cinquentões foram conquistados pela imprensa cor-de-rosa, o que explicaria o atual desprestígio das ciências humanas.

Pensamos então que uma paixão tão desesperada por pontos tão estreitos da doutrina era um sinal a ser levado em consideração; de fato, iremos ver que essa questão da imanência, tão controversa, desde muito tempo, é a pedra angular de todo o edifício teórico da semiótica.

\subsection{O que entendemos por imanência?}

Já foi observado que a posição assumida por Greimas sobre essa noção no Dicionário de semiótica (Greimas; Courtés, 2008 [1979]) foi ao mesmo tempo lacônica, circunspecta e decisiva ${ }^{12}$, a ponto de a equipe de pesquisadores - responsável, em 1986, pelo volume crítico publicado como tomo II desse mesmo Dicionário - não desejar voltar a essas formulações um tanto limitantes.

Para a semiótica greimasiana, a "Imanência" deve ser compreendida, antes de tudo, em relação à "Manifestação". Os imanentes observáveis são estruturas semióticas ditas "profundas", pois só podem ser identificadas a partir da manifestação que as pressupõe. Esses fenômenos imanentes que dão forma à manifestação devem ser buscados, portanto, sob a manifestação. Sob os signos, o sentido!, este poderia ser o slogan da semiótica imanentista e era praticamente o que estava na boca de Greimas em Cerisy-La-Salle, como lembramos anteriormente. Essas formas puramente relacionais (vazias de sentido ou muito pouco semantizadas) são invariantes ou, ao menos, fenôme- nos bastante estabilizados e, portanto, previsiveis, os quais o progresso da pesquisa permite, cada vez mais, que sejam considerados como universais. O /quadrado semiótico/ ou os esquemas de narratividade abstrata oferecem exemplos aceitáveis desse gênero de formas. A atualização de tais estruturas e das relações que as colocam em redes é o objetivo principal, a razão de ser e a identidade singular da semiótica teorizada e praticada pelos emuladores de F. de Saussure.

Um trabalho experimental que recorre a modelos já validados por essa teoria permite chegar a níveis de sentido que a aproximação intuitiva, não instrumentalizada, não poderia identificar ${ }^{13}$. Isso é o que nutre e faz progredir o saber semiótico, dotado de uma presença na imanência, disponível e convocável da mesma forma que os saberes da Matemática e da Física.

Em sua sistematicidade aberta a horizontes ilimitados (pois que indexados nosalargamentos sucessivos do saber), o termo Imanência designa e figurativiza o espaço mental instaurado pelas primeiras impressões de Saussure e de todos aqueles que tentaram, com algum sucesso, implementar suas ideias sobre as significações. Esse espaço mental pode ser descrito como aquele do conjunto das formas abstratas, suportes da intuição/certeza que acompanha a manipulação de novas modalidades de objetivação a cada vez que a história das ciências registra uma mudança de paradigma. Lembramo-nos de Descartes, decidido a fazer uso de:

\begin{abstract}
[...] algumas noções gerais relativas à Física [...], notei até onde podiam conduzir, e o quanto diferem dos princípios que foram utilizados até o presente [...] Pois elas me fizeram ver que é possivel chegar a conhecimentos que sejam muito úteis à vida, e que, em vez dessa Filosofia especulativa que se ensina nas escolas, se pode encontrar uma outra prática, pela qual, conhecendo a força e as ações do fogo, da água, do ar, dos astros, dos céus e de todos os outros corpos que nos cercam, tão distintamente como conhecemos os diversos misteres de nossos artífices, poderíamos empregá-los da mesma maneira em todos os usos para os quais são próprios, e assim nos tornar como que senhores e possuidores da natureza. (Descartes, 1987, p. 63)
\end{abstract}

As páginas finais dos Prolegômenos a uma teoria da linguagem, de Louis Hjelmslev, dizem algo semelhante ao confirmar o papel fundador atribuído por sua teoria à /Imanência $/{ }^{14}$, subentendida, mas não nomeada

\footnotetext{
${ }^{11}$ Encontra-se um eco bastante representativo desse ponto de vista sob a pluma Jean-Claude Coquet, in: "Les prédicats somatiques: notes de conférence". Littérature, n. 163, vol. 3. Comment dire sensible? Recherches sémiotiques. Paris: Larousse, 2011. pp 102-10. Disponivel em: http://www.cairn.info/article.php?ID_ARTICLE=LITT_163_0102

12 Esses três adjetivos se aplicam à expansão promovida por J. F. Bordron a essa entrada do Dicionário, na sua contribuição em Puebla, em junho de 2014, com o artigo "La inmanencia radical" (Tópicos del seminario. Revista de semiotica, vol. 2, n. 32. Disponível em: http://www.topicosdelseminario.buap.mx/index.php/topsem/article/view/343. Encontraremos, nesse texto, redigido com firme claridade, um bom número de respostas às contestações, frequentemente pouco ou mal informadas, das quais a teoria imanentista da semiótica saussuriana foi e permanece sendo objeto.

13 Pedimos desculpas por essa autorreferência que permite ilustrar narrativamente esse fato: dedicamos pesquisas bastante longas à parábola que termina por constituir a relação Greimas/Ricoeur. Remetemos o leitor aos artigos, fruto desta pesquisa, mencionados nas referências (Hénault, 2016 e 2017).

14 /imanência/? Esses /.../ são, para a semiótica, o sinal tipográfico de pertencimento e de emprego de um dado termo segundo o valor que lhe é conferido pela metalinguagem Semiótica.
} 
nas primeiras observações de Saussure:

A teoria da linguagem [...] Em seu ponto de partida, ela se baseara na imanência, atribuindo-se por único objetivo a constância, o sistema e a função interna; aparentemente, isso deveria ser feito às custas das flutuações e dos matizes, às custas da vida e da realidade concreta, física e fenomenológica. Uma limitação provisória de nosso campo visual era o preço que se devia pagar para arrancar da linguagem seu segredo. Ora, é graças a este ponto de vista imanente que a linguagem devolve generosamente aquilo que, de início, ela exigira. A linguagem, considerada num sentido mais amplo que aquele que lhe é atribuído pela linguística contemporânea, retomou sua posição-chave no domínio do conhecimento. Em vez de impedir a transcendência, a imanência, pelo contrário, deu-lhe uma base nova e mais sólida. A imanência e a transcendência juntam-se numa unidade superior baseada na imanência. A teoria linguística, por necessidade interna, é levada a reconhecer não apenas o sistema linguístico em seu esquema e seu uso, em sua totalidade assim como em seus detalhes, mas também o homem e a sociedade humana presentes na linguagem e, através dela, a atingir o domínio do saber humano em sua totalidade. Com isso, a teoria da linguagem atingiu a finalidade que se tinha atribuído: humanitas et universitas. (Hjelmslev, 2003, 132-133)

Destaquemos a insistência de Hjelmslev no fato de que a teoria da linguagemé guiada racionalmente em seu desenvolvimento, que ela é "conduzida pela necessidade interna”; e ao menos nisso não se diferencia em nada das matemáticas, da física e de qualquer outro campo do saber racional.

Destaquemos também o quanto a máxima latina com a universalidade, significada pelo termo ciceroniano Universitas, é jubilosa e dilatadora, a exemplo do fim do texto de Descartes citado acima.

É verdade que a ampliação das perspectivas epistemológicas que tinham sido trazidas por Einstein (assim como por diversos outros pesquisadores, como Felix Klein, a propósito da pluralidade das geometrias e dos jogos de linguagem que elas implicam) estilhaçaram um bom número de certezas inspiradas pela razão pura de Kant ${ }^{15}$. A passagem do transcendental ao semiótico se colocava como um acesso a outras formas de objetivação do saber, entre as quais a objetivação dos saberes sobre a linguagem, que teve em Saussure, Husserl, Cassirer ou Hjelmslev o começo de seu aprofundamento. Isso numa atitude mental que não tinha nenhuma relação dogmática com o sentido, mas que era vivida como um fascínio por novas práticas que seriam assim induzidas (exatamente como lemos o guia para a prática no texto de Descartes citado acima).
A força da teoria semiótica standard de Greimas se afirma pela maneira como ele soube renovar as práticas do sentido com a radicalidade de seu trabalho em Imanência, tal qual se lê notadamente em Semântica estrutural, nos dois volumes de Sobre o sentido ou em Maupassant (1993 [1976]). A. J. Greimas construiu a semiótica retomando, ao pé da letra, a aposta hjelmsleviana de objetivação das significações pelo princípio da imanência.

Até aqui, a fragilidade das pesquisas dedicadas ao sensível, ao passional ou aos diversos aspectos do vivido provém do fato de que elas ainda não puderam efetuar o trabalho de abstração que colocaria seus resultados nesse mesmo campo da imanência.

Longe de ser um espaço mental bloqueado, o que imaginam alguns entre nós, uma pesquisa semiótica guiada pela atualização do (ou dos) plano(s) de imanência que dá(dão) forma ao sistema complexo de relações constitutivas das diversas linguagens: (i) realiza-se ampliando sem cessar seu domínio de pertinência; (ii) descobre-se pela observação e análise das regularidades abstratas que o caracterizam; (iii) sistematiza-se pela reconstituição das gramáticas abstratas que o configuram.

Nisso consiste, para nós, uma representação do que terá sido, para A. J. Greimas, um programa aceitável para o estudo da significação, isto é, um projeto teórico em construção.

\section{Referências}

Arrivé, Michel.

2007. A la recherche de Ferdinand de Saussure. Paris: PUF.

Arrivé, Michel; Coquet, Jean-Claude.

1987. Sémiotique en jeu. A partir et autour de l'oeuvre d'A. J. Greimas. Paris/ Amsterdam/Philadelphia: Hadès-Benjamins.

Benveniste, Émile.

1976. Problèmes de linguistique générale I et II. Paris: Gallimard.

Cobley, Paul (éd.).

2010. The Routledge Companion to Semiotics. London: Routledge.

\section{Descartes, René}

1987. Discurso do método. Trad. Jaime Guinsburg e Bento Prado Júnior. Introdução de Gilles-Gaston Granger, com prefácio e notas de Gérard Lebrun. São Paulo: Nova Cultural.

\footnotetext{
2016.

15 Sobre a transformação das categorias do pensamento registrada pela História das Ciências nesse período crucial, ver Jean Lassègue,
} 
Emmeche, Claus; Favareau, Donald.

2008. Essential Readings in Biosemiotics: Anthology and Commentary. Berlin: Springer.

Greimas, Algirdas Julien.

1966. Sémantique structurale. Paris: PUF, 1966.

Greimas, Algirdas Julien.

1976. Semântica estrutural. Trad. Haquira Osakabe e Izidoro Blikstein. São Paulo: Cultrix/EDUSP.

Greimas, Algirdas Julien.

1970. Du Sens. Paris: Seuil.

Greimas, Algirdas Julien.

1975. Sobre o sentido. Trad. Ana Cristina Cruz Cezar et alli. Petrópolis: Vozes.

Greimas, Algirdas Julien.

1983. Du Sens II. Paris: Seuil.

Greimas, Algirdas Julien.

2014. Sobre o sentido II. Trad. Dilson Ferreira da Cruz. São Paulo: Nankin/EDUSP.

Greimas, Algirdas Julien.

1976. Maupassant: la sémiotique du texte. Paris: Seuil.

Greimas, Algirdas Julien.

1993. Maupassant: a semiótica do texto: exercícios práticos. Trad. Teresinha Oenning Michels e Carmen Lúcia Cruz Lima Gerlach. Florianópolis: EDUFSC, 1993.

Greimas, Algirdas Julien.

1985. Des dieux et des hommes.Paris: PUF.

Greimas, Algirdas Julien.

2000. La mode en 1830. Paris: PUF.
Greimas, Algirdas Julien; Courtés, Joseph. 1979. Sémiotique. Dictionnaire raisonné de la théorie du langage. Paris: Hachette.

Greimas, Algirdas Julien; Courtés, Joseph. 2008. Dicionário de Semiótica. Trad. Alceu Dias Lima et alli. São Paulo: Contexto.

Hénault, Anne.

1994. Le pouvoir comme passion. Avec le débat GreimasRicoeur, 1989. Paris: PUF.

Hénault, Anne.

1997. Histoire de la sémiotique. Paris: PUF.

Hénault, Anne.

2002. Questions de sémiotique. Paris: PUF.

Hénault, Anne.

2016. Ricoeur, a disciple of Greimas? A case of paradoxical maieutic. Actes du XII Congrès Mondial AIS/IASS- International Association for Semiotic Studies/ Association Internationale de Sémiotique. Sofia: Mouton De Gruyter.

Hénault, Anne.

2017. Quelles pratiques sémiotiques pour quelles mediations? Texto livre, vol. 10, n. 1. Belo Horizonte. Disponivel em: http://www.periodicos.letras. ufmg.br/index.php/textolivre/article/ viewFile/11731/10466

Hjelmslev, Louis.

2003. Prolegômenos a uma teoria da linguagem. Trad. J. Teixeira Coelho Netto. São Paulo: Perspectiva.

Lassègue, Jean.

2016. Ernst Cassirer, du transcendantal au sémiotique. Paris: Vrin. 


\section{Dados para indexação em língua estrangeira}

Hénault, Anne

A. J. Greimas, un projet théorique en construction

Estudos Semióticos, vol. 13, n. 2 (2017)

ISSN 1980-4016

Résumé: Après un rappel des principales étapes par lesquelles Greimas a traversé la linguistique pour fonder concrètement la sémiotique générale, nous avons indiqué comment le concept d'immanence définit l'identité même de la sémiotique que Greimas invitait à construire et à pratiquer. Le principe d'immanence est l'instrument conceptuel qui permet de mettre au jour, de décrire et de hiérarchiser les jeux relationnels abstraits qui constituent la grammaire profonde des langues et du langage. Le savoir nouveau qui résulte de l'émergence de la sémiotique est tout entier lié à ce type de fonctionnement mental dont le savoir mathématique constitue un autre exemple.

Mots-clés: Immanence ; théorie ; métalangage ; pratique ; grammaires abstraites

\section{Como citar este artigo}

HÉnAult, Anne. A. J. Greimas, um projeto teórico em construção. Estudos Semióticos. [on-line], volume 13, n. 2 (edição especial). Editores convidados: Waldir Beividas e Eliane Soares de Lima. São Paulo, dezembro de 2017, p. 6-12. Disponível em: (www.revistas.usp.br/esse ). Acesso em "dia/mês/ano".

Data de recebimento do artigo: 18/06/2017

Data de sua aprovação: 05/08/2017 